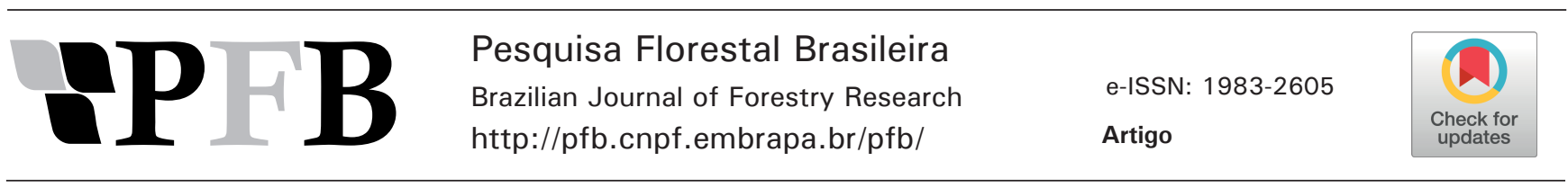

\title{
Florística e diversidade da regeneração natural em clareiras em Floresta Ombrófila Mista
}

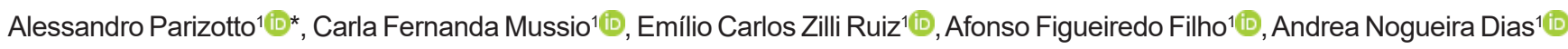 \\ ${ }^{1}$ Universidade Estadual do Centro-Oeste, PR 153 Km 7, Riozinho, CEP 84500-000, Irati, PR, Brasil
}

*Autor correspondente:

alessandroparizotto@gmail.com

Termos para indexação:

Componente arbóreo

Sucessão ecológica

Similaridade florística

Index terms:

Arboreal component

Ecological succession

Floristic similarity

Histórico do artigo:

Recebido em 18/08/2018

Aprovado em 13/03/2019

Publicado em 16/07/2019

\section{(c) $(1)$}

Trabalho apresentado no V Seminário de Atualização Florestal, 24 e 28 de setembro de 2018, Irati, PR.
Resumo - O presente trabalho teve como objetivo avaliar a florística e a diversidade do componente arbóreo regenerante em sete áreas de clareiras formadas pelo manejo seletivo da araucária em remanescentes de Floresta Ombrófila Mista. O índice de Shannon foi utilizado para a análise da diversidade florística e o de Jaccard para relacionar as similaridades existentes em cada área de clareira. Foi também realizada a classificação das espécies em grupos ecológicos, por meio de revisão de literatura. Observou-se maior riqueza de espécies nas famílias Myrtaceae e Salicaceae. Araucariacea não apresentou grande número de indivíduos. As áreas de clareiras estudadas apresentaram baixa semelhança, quando utilizou-se o índice de Jaccard com linha de corte de 50\%, indicando alta variabilidade de espécies. Com a linha de corte em $40 \%$ ocorreu formação de três grupos distintos. O grupo ecológico das secundárias iniciais foi o mais representativo em termos de riqueza espécies, por se tratar de regeneração natural em clareiras recém-formadas, indicando um estágio inicial de sucessão nessa nova etapa de evolução da floresta.

\section{Floristic and diversity of natural regeneration in clearing areas in Araucaria Forest}

\begin{abstract}
The objective of this reserach was to evaluate and compare data on floristic and natural regeneration diversity in seven clearing areas formed by the selective management of araucaria in remnants of Araucaria Forest. The indices of Shannon and Jaccard were used, respectively, to analyze the floristic diversity and to relate the similarities in each clearing area. The classification of the species into ecological groups was based on literature review. The families Myrtaceae and Salicaceae presented the biggest frequency of species. Araucariaceae did not present a significant number of individuals. The similarity analysis according to Jaccard index with cut line at 50\% showed low similarity between the studied clearing areas, indicating high species variability. When using the cut line of $40 \%$, three distinct groups were formed. The ecological group of the initial secondary species was the most representative, as expected due to the natural regeneration in newly formed clearings, indicating an initial successional stage in the new stage of forest evolution.
\end{abstract}




\section{Introdução}

A Floresta Ombrófila Mista ou Floresta com Araucária é uma tipologia florestal formada pela mistura de espécies de diferentes origens, com presença marcante de elementos Coniferales e Laurales (Leite \& Klein, 1990). É uma unidade fitogeográfica de grande importância ecológico-econômica, por sua característica única de abrigar a conífera mais expressiva da vegetação brasileira, Araucaria angustifolia (Bertol.) Kuntze. (Narvaes et al., 2005).

Do ponto de vista social, a Floresta Ombrófila Mista pode ser também uma importante fonte de renda, pois possibilita a coleta do pinhão e outros produtos madeireiros (e.g espécies das famílias Lauraceae e Fabaceae) e não madeireiros (Higuchi et al., 2012; Carvalho et al., 2008). Como exemplo de produtos não madeireiros, podemos citar espécies frutíferas da família Myrtaceae, as folhas e ramos da erva-mate (Ilex paraguariensis A. St. Hil.), espécies com potencial medicinal, como a espinheira-santa (Maytenus ilicifolia Mart. ex Reissek) e epífitas de espécies das famílias Bromeliaceae e Orquidaceae, com potencial ornamental (Sanquetta et al., 2010).

Accioly (2013), em estudo realizado por meio de sensoriamento remoto, constatou que $18,5 \%$ da área total do Estado do Paraná são compostos por florestas nativas. Dessa área, 50,4\% são de Floresta Ombrófila Mista em diferentes estágios de sucessão, caracterizando uma paisagem fragmentada. A drástica redução de sua área natural a torna uma das tipologias mais ameaçadas da região Sul. Diante desse cenário, é de grande importância o estudo de diferentes estratégias para sua conservação, sendo o manejo sustentável madeireiro e não madeireiro, pautado nos princípios da sustentabilidade, uma forma de conservar a floresta.

Para que o embasamento das decisões a serem tomadas possa garantir o sucesso do manejo florestal sustentável, estudos anteriores de caracterização do ambiente florestal devem ser elaborados para que se possa alcançar o conhecimento que viabilize a exploração de seus produtos, bens e serviços, de forma planejada, para garantir seu fluxo contínuo (Austregésilo et al., 2004). É essencial, também, compreender como a floresta reage após a prática do manejo. Assim, o conhecimento sobre a regeneração natural é uma das formas de se avaliar a sustentabilidade da floresta em questão, sob o ponto de vista da sua capacidade de renovação em termos quantitativos e qualitativos.

Além da importância de informações sobre regeneração natural para o sucesso do manejo florestal (Daniel \& Jankausukis, 1989), os resultados dos estudos sobre essa temática auxiliam na elaboração de sistemas silviculturais (Carvalho, 1997), contribuem para práticas de manutenção de espécies ameaçadas e fornecem informações para construção de pressupostos para recuperação de áreas degradadas (Begon et al., 2007). Devido à importância e aplicabilidade de resultados dessa natureza, diversos trabalhos foram realizados em áreas conservadas (Avila et al., 2013; Dalla Rosa et al., 2016; Narvaes et al., 2005, 2008; Santos et al., 2015; Silva et al., 2010; Souza et al., 2012; Valente et al., 2010; entre outros) em diferentes fitofisionomias sob diferentes condições, onde, na maioria dos casos, os resultados tentam esclarecer a forma como o recrutamento, o desenvolvimento e a sobrevivência das plântulas regulam o crescimento e a manutenção das populações arbustivo-arbóreas (Denslow, 1991).

Contudo, ainda são poucos os estudos sobre regeneração natural em áreas antropizadas, podendo ser citados os realizados por Mauhs \& Backes (2002) e Onofre et al. (2010). Considerando esse cenário, o presente estudo objetivou analisar a florística e diversidade da regeneração natural em área antropizada pela abertura de clareiras, após atividades de pesquisa de manejo seletivo da araucária em Floresta Ombrófila Mista.

\section{Material e métodos}

O remanescente florestal avaliado neste estudo está localizado no Município de Fernandes Pinheiro, região Centro-Sul do Paraná. Esse remanescente faz parte do projeto de extensão e pesquisa "Estratégias para o Manejo Florestal Sustentável em Pequenas Propriedades Rurais no Centro-Sul do Paraná, Brasil", desenvolvido pelo laboratório de Manejo Florestal do Departamento de Engenharia Florestal da Unicentro, que tem como objetivo geral promover o desenvolvimento rural sustentável. Estão inseridas neste projeto 36 pequenas propriedades rurais, nas quais diversas atividades de extensão e pesquisa vêm sendo realizadas desde 2011 e incluía a pesquisa autorizada sobre manejo florestal da Floresta Ombrófila Mista. 
O município de Fernandes Pinheiro localiza-se na região Centro-Sul do Paraná $\left(25^{\circ} 25^{\prime}\right.$ S e $\left.50^{\circ} 32^{\prime} \mathrm{W}\right)$, na microrregião de Prudentópolis. A altitude média é de 893 m e o clima da região, segundo a classificação de Köppen, é do tipo $\mathrm{Cfb}$, subtropical úmido sem estação seca, com precipitação média anual de $1.442 \mathrm{~mm}$, com temperatura média do mês mais quente inferior a $22^{\circ} \mathrm{C}$ e a média do mês mais frio superior a $10^{\circ} \mathrm{C}$, com mais de cinco geadas por ano (Carvalho, 1980). A vegetação predominante da região é classificada como Floresta Ombrófila Mista Montana (IBGE, 2012).

\section{Amostragem}

A regeneração natural de espécies arbóreas foi avaliada em sete áreas de clareira (Figura 1) formadas pela pesquisa em manejo seletivo sustentável da araucária em uma área de 2 ha. A amostragem foi realizada aproximadamente um ano após a exploração, pela instalação de transectos permanentes de $10 \mathrm{~m}$ de comprimento, iniciando na base da árvore manejada em direção à área de queda.
Figura 1- Clareiras formadas pelo manejo seletivo sustentável da araucária, em Fernandes Pinheiro, PR.

Figure 1. Clearing areas formed by selective sustainable forest management of araucaria, Fernandes Pinheiro, Parana State.
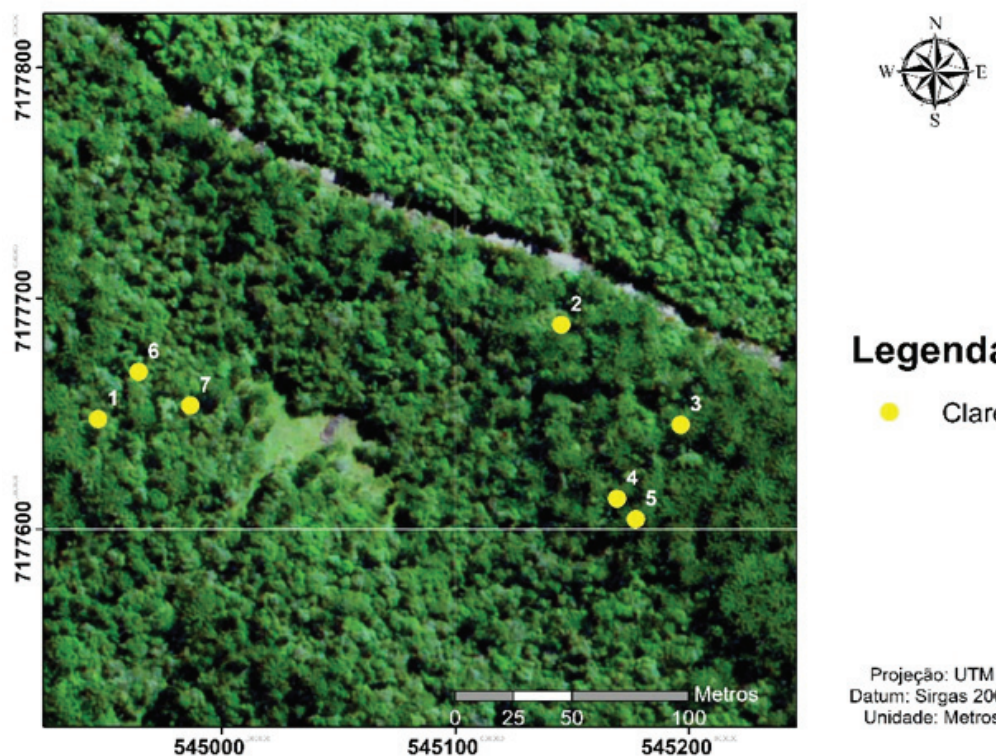

Legenda

Clareiras
Projeçăa: UTM Datum: Sirgas 2000 Unidade: Metros
Os indivíduos do componente arbóreo regenerante foram divididos em três classes de tamanho, adaptandose a metodologia proposta por Finol (1972): classe I: plantas com altura entre $0,3 \mathrm{~m}$ e $1 \mathrm{~m}$; classe II: plantas com altura entre $1,01 \mathrm{~m}$ e $3 \mathrm{~m}$; classe III: plantas com altura acima de 3,01 $\mathrm{m}$ e com no máximo $9,9 \mathrm{~cm}$ de diâmetro a 1,30 m do solo (DAP).

As classes de tamanho foram amostradas em parcelas de tamanho diferenciado, prosseguindo da seguinte forma: com o auxílio da trena foi mensurado para cada lado do transecto, $1 \mathrm{~m}$ para a Classe I, $3 \mathrm{~m}$ para a Classe II e $7 \mathrm{~m}$ para a Classe III, totalizando $20 \mathrm{~m}^{2}, 60 \mathrm{~m}^{2} \mathrm{e}$ $140 \mathrm{~m}^{2}$, respectivamente. Foram avaliadas sete clareiras, totalizando uma área amostrada de $140 \mathrm{~m}^{2}, 420 \mathrm{~m}^{2} \mathrm{e} 980 \mathrm{~m}^{2}$ para as Classes I, II e III, respectivamente.

Nem todos os indivíduos amostrados puderam ser identificados em nível de epíteto específico, devido ao estágio inicial de desenvolvimento que a plântula se encontrava. Para esses casos, os indivíduos foram considerados como não identificados e numerados para acompanhamento até possível identificação. Para os demais, a identificação botânica das espécies ocorreu em campo por meio de suas características morfológicas. Foi coletado material botânico das espécies não identificadas em campo, para posterior identificação por especialistas. Os exemplares coletados se encontram armazenados no Herbário do curso de Engenharia Florestal da Unicentro (HUCO) e foram classificados seguindo o The Angiosperm Phylogeny Group (APG, 2016) e The Internacional Plant Names Index (IPNI, 1999).

\section{Florística e diversidade}

A diversidade florística foi analisada pelo índice de Shannon (Equação 1). A média ponderada do índice foi calculada para as três classes. 


$$
H^{\prime}=-\sum \frac{n_{i}}{N} \times \ln \frac{n_{i}}{N}
$$

Em que: $\mathrm{H}^{\prime}$ = índice de Shannon; $\mathrm{n}$ = número de indivíduos da espécie; $\mathrm{N}=$ número total de indivíduos; $\ln =$ logaritmo de base natural.

O índice de Similaridade de Jaccard foi utilizado para avaliar a florística entre as diferentes áreas de clareira (Equação 2). Para a obtenção dos índices e do dendrograma, foi utilizado o software Past ${ }^{\circledR} 2.17$ c.

$$
J=\frac{S_{c o m}}{S_{1}+S_{2}+S_{c o m}}
$$

Em que: $\mathrm{J}$ = índice de Jaccard; $\mathrm{S}_{\text {com }}=$ número de espécies em comum nas duas amostras; e $\mathrm{S}=$ número total de espécies em cada uma das amostras.

\section{Classificação de grupos ecológicos}

A classificação das espécies em função do grupo ecológico foi realizada mediante revisão de literatura (Backes \& Irgang, 2002; Carpanezi \& Carpanezi, 2006; Carvalho, 2006, 2008; Kersten et al., 2011; Lorenzi, 2008, 2009; Moscovich, 2006; Roik, 2012; Saueressig, 2014; Sawczuk, 2009; Silva et al., 2013).

\section{Resultados}

Nas sete áreas de clareira, foram contabilizados 660 indivíduos em todas as classes avaliadas, distribuídos em 28 famílias e 50 espécies classificadas ao nível específico. Dez morfoespécies foram identificadas apenas ao nível de família, sendo oito de Myrtaceae, uma de Aquifoliaceae e uma de Salicaceae e um indivíduo não foi identificado. Myrtaceae foi a família mais expressiva, com 195 indivíduos divididos em nove espécies, podendo esse número aumentar com a posterior identificação das morfoespécies pertencentes a essa família. Foram registrados 96 indivíduos de Salicaceae, distribuídos em seis espécies e a terceira família, considerando o número de indivíduos, foi Melastomataceae, com 40 indivíduos de uma única espécie.

Na classe I (plantas com altura entre $0,3 \mathrm{~m}$ e $1 \mathrm{~m}$ ), a família Myrtaceae apresentou a maior riqueza, com treze espécies incluindo as morfoespécies não identificadas. Aquifoliaceae e Salicaceae foram representadas por quatro espécies cada. Na classe II (plantas com altura entre 1,01 m e $3 \mathrm{~m}$ ) a família Myrtaceae apresentou oito espécies, incluindo as morfoespécies, Aquifoliaceae e Salicaceae, quatro. Na classe III (plantas com altura acima de 3,01 m e com no máximo 9,9 cm de diâmetro) a família Myrtaceae apresentou maior riqueza de espécies (nove, considerando as morfoespécies), seguida por Salicaceae (5) e Aquifoliaceae (3). Nas três categorias avaliadas, a maior riqueza de espécies foi encontrada na família Myrtaceae, sendo seguida por Salicaceae e Aquifoliaceae.

A classe I apresentou o maior número de indivíduos amostrados dentro das sete clareiras (274), seguida pela classe II (204) e classe III (182). Do total de indivíduos encontrados na classe I, os três mais abundantes foram Miconia cinerascens (27 indivíduos), Allophyllus edulis (26) e Curitiba prismatica (16). Para a classe II as espécies mais abundantes foram Casearia decandra (44), Curitiba prismatica (30) e Miconia cinerascens (11). Na classe III a maior ocorrência de indivíduos foi da espécie Curitiba prismatica (61) seguida pelas espécies Casearia decandra (25) e Drimys brasiliensis (18). Em se tratando de número de indivíduos por classe, percebe-se que a família Araucariaceae, representada por Araucaria angustifolia, teve uma baixa frequência de indivíduos amostrados (18 para as três classes de estudo), não sendo um número tão expressivo quando se considera que é uma das espécies que caracterizam a fitofisionomia do local de estudo.

O índice de diversidade de Shannon, para as sete clareiras englobando as três classes, apresentou média de 2,59 , sendo maior para a classe I $\left(\mathrm{H}^{\prime}=3,25\right)$, seguida pela II e III $\left(\mathrm{H}^{\prime}=2,75\right.$ e 2,42 , respectivamente) $)$.

Por meio do Índice de Similaridade de Jaccard, com linha de corte a $50 \%$ de similaridade não foram formados grupos, sendo cada área de clareira considerada distinta em termos de diversidade. Analisando os resultados com linha de corte a $40 \%$, observa-se que ocorre a formação de três grupos distintos: a área de clareira 7, área de clareira 6 e um grupo formado pelas áreas das clareiras 4, 5, 1, 2 e 3 (Figura 2).Das espécies encontradas, 10 pertencem ao grupo ecológico das pioneiras, 21 das secundárias iniciais, 13 das secundárias tardias, 5 das climácicas e apenas uma é exótica. O grupo ecológico das espécies secundárias iniciais foi o mais representativo, com $46 \%$ do total de espécies. As espécies pioneiras também foram representativas, com $24 \%$ do total de indivíduos.

As 50 espécies identificadas em nível específico foram agrupadas por grupos ecológicos e apresentadas na Tabela 1. 


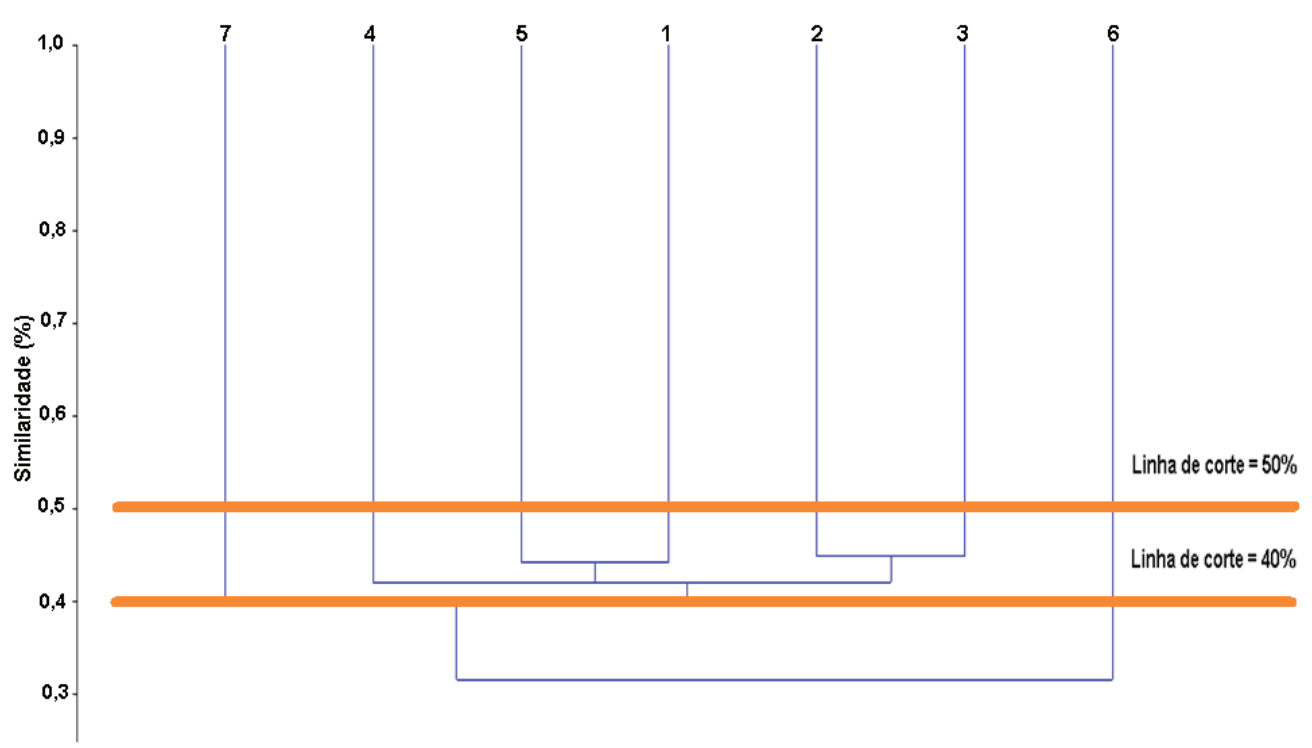

Figura 2. Dendrograma de análise de agrupamento usando o índice de similaridade de Jaccard entre clareiras, Fernandes Pinheiro, PR.

Figure 2. Dendrogram of cluster analysis using Jaccard similarity index among clearing areas, Fernandes Pinheiro, PR.

Tabela 1. Grupos ecológicos encontrados nas regiões de clareira formadas após manejo florestal, Fernandes Pinheiro, PR.

Table 1. Ecological groups registered in clearing areas following forest management, Fernandes Pinheiro, PR.

\begin{tabular}{|c|c|c|c|c|}
\hline Família & Nome científico & Nome comum & Grupo ecológico & Fonte \\
\hline Anacardiaceae & Schinus terebinthifolia Raddi & Aroeira & $\mathrm{Si}$ & Carpanezi \& Carpanezi (2006) \\
\hline \multirow[t]{3}{*}{ Aquifoliaceae } & Ilex dumosa Reissek & Cauninha & $\mathrm{Si}$ & Moscovich (2006) \\
\hline & Ilex paraguariensis A. St.-Hil. & Erva-mate & $\mathrm{Cl}$ & Carpanezi \& Carpanezi (2006) \\
\hline & Ilex theezans Mart. ex Reissek. & Caúna & $\mathrm{Si}$ & Moscovich (2006) \\
\hline Araucariaceae & Araucaria angustifolia (Bertol.) Kuntze & Araucária & $\mathrm{Cl}$ & Carpanezi \& Carpanezi (2006) \\
\hline \multirow[t]{3}{*}{ Asteraceae } & Piptocarpha axillaris (Less.) Baker & Vassourão-graúdo & $\mathrm{Pi}$ & Sawczuk (2009) \\
\hline & Piptocarpha sellowii (Sch.-Bip.) Baker & Vassourão-preto & $\mathrm{Pi}$ & Backes \& Irgang (2002) \\
\hline & Vernonanthura discolor (Spreng.) H. Rob. & Vassourão & $\mathrm{Pi}$ & Carpanezi \& Carpanezi (2006) \\
\hline Canellaceae & Cinnamodendron dinisii Schwacke & Pimenteira & $\mathrm{Pi}$ & Sawczuk (2009) \\
\hline Cannabaceae & Celtis iguanaea (Jacq.) Sarg. & Esporão-de-galo & $\mathrm{Si}$ & Backes \& Irgang (2002) \\
\hline Clethraceae & Clethra scabra Pers. & Carne-de-vaca & $\mathrm{Pi}$ & Sawczuk (2009) \\
\hline Erythroxylaceae & Erythroxylum deciduum A. St.-Hil. & Cocão & $\mathrm{Pi}$ & Sawczuk (2009) \\
\hline Euphorbiaceae & $\begin{array}{l}\text { Sebastiania commersoniana (Baill.) L. B. } \\
\text { Sm.\& Downs }\end{array}$ & Branquilho & $\mathrm{Si}$ & Carpanezi \& Carpanezi (2006) \\
\hline \multirow[t]{3}{*}{ Fabaceae } & Mimosa scabrella Benth. & Bracatinga & $\mathrm{Pi}$ & Carpanezi \& Carpanezi (2006) \\
\hline & Ateleia glazioveana Baill. & Timbó & $\mathrm{Si}$ & Carpanezi \& Carpanezi (2006) \\
\hline & Parapiptadenia rigida (Benth.) Brenan & Monjoleiro & $\mathrm{Si}$ & Carpanezi \& Carpanezi (2006) \\
\hline Lamiaceae & Vitex megapotamica (Spreng) Moldenke. & Tarumã & St & Carpanezi \& Carpanezi (2006) \\
\hline \multirow[t]{2}{*}{ Lauraceae } & Nectandra grandiflora Nees. & Caneleira & $\mathrm{Si}$ & Moscovich (2006) \\
\hline & Ocotea puberula (Rich.) Nees & Canela-guaicá & $\mathrm{Si}$ & Carpanezi \& Carpanezi (2006) \\
\hline Melastomataceae & Miconia cinerascens Miq. & Pichirica & St & Backes \& Irgang (2002) \\
\hline
\end{tabular}

Continua... 
Tabela 1. Continuação.

Tabele 1. Continuation.

\begin{tabular}{|c|c|c|c|c|}
\hline Família & Nome científico & Nome comum & Grupo ecológico & Fonte \\
\hline Monimiaceae & Mollinedia clavigera Tul. & Capixim & St & Backes \& Irgang (2002) \\
\hline \multirow[t]{9}{*}{ Myrtaceae } & Calyptranthes grandifolia O. Berg & Guamirim & $\mathrm{Si}$ & Lorenzi (2009) \\
\hline & Campomanesia xanthocarpa O. Berg & Guabiroba & St & Carvalho (2006) \\
\hline & $\begin{array}{c}\text { Curitiba prismática (D. Legrand) Salywon \& } \\
\text { L. R. Landrum }\end{array}$ & Murta & $\mathrm{Si}$ & Roik (2012) \\
\hline & Eugenia uniflora L. & Pitanga & $\mathrm{Cl}$ & Carpanezi \& Carpanezi (2006) \\
\hline & Myrcia Berg & Guamirim-ferro & St & Backes \& Irgang (2002) \\
\hline & Myrcia guianensis (Aubl.) DC. & - & $\mathrm{Cl}$ & Roik (2012) \\
\hline & Myrcia hebepetala DC. & Perta-guéla & St & Roik (2012) \\
\hline & Myrcia palustres DC. & Cambuizinho & St & Backes \& Irgang (2002) \\
\hline & Myrcianthes cisplatensis (Cambess.) O. Berg & Araçá-do-prata & $\mathrm{Si}$ & Lorenzi (2008) \\
\hline Picramniaceae & Picramnia parvifolia Engl. & Pau-amargo & St & Moscovich (2006) \\
\hline Primulaceae & Myrsine gardneriana A. DC. & Capororoca-vermelha & $\mathrm{Cl}$ & Silva et al (2013) \\
\hline Proteaceae & Roupala montana Aubl. & Carvalho & $\mathrm{Si}$ & Lorenzi (2008) \\
\hline Rhamnaceae & Hovenia dulcis Thunb. & Uva-japão & $\mathrm{E}$ & - \\
\hline Rosaceae & Prunus myrtifolia (L.) Urb. & Pessegueiro-bravo & St & Carpanezi \& Carpanezi (2006) \\
\hline Rubiaceae & Rudgea jasminoides (Cham.) Müll. Arg. & Rudgea & St & Sawczuk (2009) \\
\hline \multirow[t]{2}{*}{ Rutaceae } & $\begin{array}{l}\text { Zanthoxylum kleinii (R. S. Cowan) P. G. } \\
\text { Waterman }\end{array}$ & Juvevê & $\mathrm{Si}$ & Moscovich (2006) \\
\hline & Zanthoxylum riedelianum Engl. & Mamica & $\mathrm{Pi}$ & Lorenzi (2008) \\
\hline \multirow[t]{6}{*}{ Salicaceae } & Xylosma pseudosalzmannii Sleumer & Sucará & $\mathrm{Si}$ & Saueressig (2014) \\
\hline & Banara tomentosa Clos & Banara & $\mathrm{Pi}$ & Backes \& Irgang (2002) \\
\hline & Casearia decandra Jacq. & Guaçatunga-branca & $\mathrm{Si}$ & Moscovich (2006) \\
\hline & Casearia lasiophylla Eichler & Guaçatunga-pilosa & $\mathrm{Si}$ & Sawczuk (2009) \\
\hline & Caseria sylvestris $\mathrm{Sw}$ & Guaçatunga-preta & $\mathrm{Si}$ & Roik (2012) \\
\hline & Casearia oblique Spreng. & Guaçatunga-vermelha & $\mathrm{Si}$ & Sawczuk (2009) \\
\hline \multirow[t]{2}{*}{ Sapindaceae } & $\begin{array}{l}\text { Allophylus edulis (A. St- Hil., Cambess e A. } \\
\text { Juss.) Radlk. }\end{array}$ & Vacum & $\mathrm{Si}$ & Saueressig (2014) \\
\hline & Matayba elaeagnoides Radlk. & Miguel-pintado & St & Carvalho (2006) \\
\hline Solanaceae & Solanum granuloso-leprosum Dunal & Fumeiro-bravo & $\mathrm{Pi}$ & Carpanezi \& Carpanezi (2006) \\
\hline Styracaceae & Styrax leprosus Hook. \& Arn. & Canela-raposa & St & Carvalho (2006) \\
\hline Symplocaceae & Symplocos tetrandra (Mart.) Miq. & Sete-sangria & $\mathrm{St}$ & Sawczuk (2009) \\
\hline Winteraceae & Drimys brasiliensis Miers. & Cataia & $\mathrm{Si}$ & Sawczuk (2009) \\
\hline
\end{tabular}

Em que: $\mathrm{Pi}=$ pioneira; $\mathrm{Si}$ = secundária inicial; $\mathrm{St}$ = secundária tardia $\mathrm{Cl}$ = climácica; $\mathrm{E}=$ exótica.

\section{Discussão}

O maior número de espécies (9) de regeneração natural da família Myrtaceae também foram encontrados por Santos et al. (2015), em um fragmento de Floresta Ombrófila Mista em Lages, SC, sendo relatado por esses autores o mesmo número de espécies. Em um remanescente de Floresta Estacional Decidual, Sccoti et al. (2011) também encontraram o maior número de espécies de regeneração natural dentro da família Myrtaceae, seguida por Meliaceae e Sapindaceae.

O baixo número de indivíduos de araucária tem sido frequentemente relatado em estudos sobre regeneração natural de Floresta Ombrófila Mista (Silva et al., 2010; Souza et al., 2012). Em longo prazo, isso pode comprometer a manutenção dessas populações (Souza et al., 2012). Segundo Silva et al. (2010), dificilmente essa espécie estabelecerá uma nova população adulta 
no interior da floresta. Esses autores justificam essa afirmação pela limitação de dispersão das sementes ou por dificuldades no estabelecimento e sobrevivência de regenerantes no interior da floresta já desenvolvida.

É válido ressaltar que no interior da floresta, em áreas conservadas, a regeneração natural da araucária possa ser comprometida, onde o baixo número de indivíduos regenerantes poderia indicar alteração em longo prazo da estrutura da Floresta Ombrófila Mista. Assim, o monitoramento do comportamento e evolução dos regenerantes dessa e de outras espécies e é de extrema importância, para ações direcionadas à conservação da floresta natural.

Santos et al. (2015) encontraram um índice de diversidade de Shannon de 2,73, sendo um pouco superior ao encontrado no presente estudo $\left(\mathrm{H}^{\prime}=2,59\right)$. Avila et al. (2013) também encontraram valor mais elevado $(3,06)$. É notável como a diversidade diminui no sentido da classe I para classe III, quando os dados de todas as clareiras são analisados em conjunto. Possivelmente, isso ocorreu devido à abertura das clareiras, aumentando a luminosidade da área e dando condições favoráveis à germinação dos bancos de sementes persistentes e transitórios. Essas condições elevaram a abundância de indivíduos na classe I, o que aumenta a probabilidade de maior diversidade de espécies, pois o processo de regeneração natural dentro das áreas em processos de restauração é considerado um dos descritores mais eficientes para o aumento da diversidade (Andrade et al., 2018).

Vale ressaltar a presença da espécie exótica Hovenia dulcis Thunb., que representa $2 \%$ do total de espécies classificadas nos grupos ecológicos. Essa espécie foi considerada por Lazzarin et al. (2015) como invasora da Floresta Ombrófila Mista, requerendo essa situação uma atenção especial.

A família Myrtaceae, por apresentar o maior número de espécies nas clareiras estudadas, também se mostrou a família mais variada com relação aos grupos ecológicos, apresentando espécies com características secundárias iniciais, secundárias tardias e clímax.

Avila et al. (2013), em análise dos grupos ecológicos, encontraram em sua avaliação resultados diferentes dos obtidos neste trabalho, com $30 \%$ das espécies classificadas como pioneiras ou secundárias iniciais e 40\% como secundárias tardias ou climácicas. A diferença de resultados pode ser explicada pelo fato de as áreas de clareiras estarem em processo inicial de formação, ou seja, em processo de dinâmica da regeneração, podendo resultar em alterações da formação de grupos ecológicos.

O conhecimento e análise dos dados obtidos pelo presente estudo se tornam importantes por subsidiar tomadas de decisões para o desenvolvimento e implantação de plano de manejo sustentável de floresta nativa adequado, visando respeito ao ciclo natural da Floresta Ombrófila Mista.

\section{Conclusões}

A regeneração natural em áreas de clareiras apresentou-se variada, com altos índices de diversidade principalmente na menor classe. O Índice de Similaridade de Jaccard com corte de $40 \%$ mostrou a formação de grupos distintos, sendo um ponto positivo a se considerar em estudos de regeneração da floresta, pois indica uma diversificada combinação de espécies.

As famílias mais representativas do estudo foram Myrtaceae e Salicaceae, sendo registrada baixa frequência de Araucaria angustifolia, espécie característica da fitofisionomia da Floresta Ombrófila Mista.

Espécies secundárias iniciais apresentaram grande representatividade no estudo, evidenciando que as condições de desenvolvimento estabelecidas em áreas de clareiras favorecem essas espécies.

\section{Referências}

Accioly, P. Mapeamento dos remanescentes vegetais arbóreos do estado do Paraná e elaboração de um sistema de informações geográficas para fins de análise ambiental do estado. 2013. 127 f. Tese (Doutorado em Engenharia Florestal) - Universidade Federal do Paraná, Curitiba.

Andrade, G. K. O. et al. Regeneração natural em área de reflorestamento misto com espécies nativas no município de Laranjeiras, SE. Revista de Ciências Agrárias, v. 61, 2018. https:// doi.org/10.22491/rca.2018.2779

APG. The Angiosperm Phylogeny Group. An update of the angiosperm phylogeny group classification for the orders and families of flowering plants: APG IV. Botanical Journal of the Linnean Society, v. 181, p. 1-20, 2016. http://dx.doi.org/10.1111/boj.12385.

Austregésilo, S. L. et al. Comparação de métodos de prognose da estrutura diamétrica de uma Floresta Estacional Semidecidual secundária. Revista Árvore, v. 28, n. 2, p. 227-232, 2004. https:// doi.org/10.1590/s0100-67622004000200009.

Avila, A. L. et al. Mecanismos de regeneração natural em remanescente de Floresta Ombrófila Mista, RS, Brasil. Cerne, v. 19, n. 4, p. 621-628, 2013. DOI: 10.1590/S0104-77602013000400012. 
Backes, P. \& Irgang, B. Árvores do Sul: guia de identificação e interesse ecológico. Santa Cruz do Sul: Instituto Souza Cruz, 2002. $325 \mathrm{p}$.

Begon, M. et al. Ecologia: de indivíduos a ecossistemas. 4. ed. Porto Alegre: Artmed, 2007. 752 p.

Carpanezzi, A. A. \& Carpanezzi, O. T. B. Espécies nativas recomendadas para recuperação ambiental no Estado do Paraná, em solos não degradados. Colombo: Embrapa Florestas, 2006. 57p.

Carvalho, J. O. P. Dinâmica de florestas naturais e sua implicação para o manejo florestal. In: CURSO DE MANEJO FLORESTAL SUSTENTÁVEL, 1., 1997, Curitiba. Tópicos em manejo florestal sustentável. Colombo: EMBRAPA-CNPF, 1997. p. 43-55. (EMBRAPA-CNPF. Documentos, 34).

Carvalho, P. E. Levantamento florístico da região de Irati-PR (1a aproximação). Curitiba: EMBRAPA-URPFCS, 1980. (EMBRAPAURPFCS. Circular técnica, 3).

Carvalho, P. E. R. Espécies arbóreas brasileiras. v. 2. Brasília, DF: Embrapa Floresta. 2006. 627 p.

Carvalho, P. E. R. Espécies arbóreas brasileiras. v. 3. Brasília, DF: Embrapa Floresta, 2008. 593 p.

Dalla Rosa, A. et al. Natural regeneration of tree species in a cloud forest in Santa Catarina, Brazil. Revista Árvore, v. 40, n. 6, p.10831092, 2016. http://dx.doi.org/10.1590/0100-67622016000600013.

Daniel, O. \& Jankauskis, J. Avaliação de metodologia para o estudo do estoque de sementes do solo. Série IPEF, v. 41-42, p. 18-26, 1989.

Denslow, J. S. The effect of understory palms and cyclanths on the growth and survival of Inga seedlings. Biotropica, v. 23, n. 3, p. 225-234, 1991. https://doi.org/10.2307/2388199.

Finol, U. H. Nuevos parámetros a considerarse en el análisis estructural de las selvas vírgenes tropicales. Revista Forestal Venezolana, v. 14, n. 21, p. 29-42, 1972.

Higuchi, P. et al. Influência de variáveis ambientais sobre o padrão estrutural e florístico do componente arbóreo, em um fragmento de Floresta Ombrófila Mista Montana em Lages, SC. Ciência Florestal, v. 22, n. 1, p. 79-90, 2012. https://doi.org/10.5902/198050985081.

IBGE. Manual técnico da vegetação brasileira. 2. ed. Rio de Janeiro, 2012. 271 p. (Série: Manuais técnicos em geociências n. 1).

IPNI. The International Plant Names Index. 1999. Disponível em $<$ http://www.ipni.org/ipni>. Acesso em outubro 2018.

Kersten, R. A. et al. Floresta Ombrófila Mista: aspectos fitogeográficos, ecológicos e métodos de estudo. Fitossociologia no Brasil: métodos e estudos de caso: volume II. Viçosa, MG: Ed. UFV, 2011. 556 p.

Lazzarin, L. C. et al. Invasão biológica por Hovenia dulcis Thunb. em fragmentos florestais na região do Alto Uruguai, Brasil. Revista Árvore, v. 39, n. 6, p. 1007-1017, 2015. http://dx.doi. org/10.1590/0100-67622015000600003.

Leite, P. F. \& Klein, R. M. Vegetação. In: IBGE. Geografia do Brasil: região Sul. Rio de Janeiro: IBGE, 1990. p. 113-150.

Lorenzi, H. Árvores brasileiras: manual de identificação e cultivo de plantas arbóreas nativas do Brasil. 5. ed. Nova Odessa, SP: Instituto Plantarum, 2008. v. 1.
Lorenzi, H. Árvores brasileiras: manual de identificação e cultivo de plantas arbóreas nativas do Brasil. Nova Odessa, SP: Instituto Plantarum, 2009. v. 3. 384 p.

Mauhs, J. \& Backes A. Estrutura fitossociológica e regeneração natural de um fragmento de Floresta Ombrófila Mista exposta a perturbações antrópicas. Pesquisas, Botânica, v. 52, p. 89-109, 2002.

Moscovich, F. A. Dinâmica de crescimento de uma Floresta Ombrófila Mista em Nova Prata, RS. 2006. 135 f. Tese (Doutorado em Engenharia Florestal) - Universidade Federal de Santa Maria, Santa Maria, RS.

Narvaes, I. S. et al. Estruturas da regeneração natural em Floresta Ombrófila Mista na Floresta Nacional de São Francisco de Paula, RS. Ciência Florestal, v. 15, n. 4, p. 331-342. 2005. http://dx.doi. org/10.5902/198050981871.

Narvaes, I. S. et al. Florística e classificação da regeneração natural em Floresta Ombrófila Mista na Floresta Nacional de São Francisco de Paula, RS. Ciência Florestal, v. 18, n. 2, p. 233-245, 2008. http:// dx.doi.org/ 10.5902/19805098460.

Onofre, F. F. et al. Regeneração natural de espécies da Mata Atlântica e sub-bosque de Eucalyptus saligna Smith. em uma antiga unidade de produção florestal no Parque das Neblinas, Bertioga, SP. Scientia Forestalis, v. 38, n. 85, p. 39-52, 2010.

Roik, M. Dinâmica (2002-2011) e modelagem do incremento diamétrico em fragmento de Floresta Ombrófila Mista na Floresta Nacional de Irati, Paraná. 2012. 141 f. Dissertação (Mestrado em Ciências Florestais) - Universidade Estadual do Centro-Oeste, Irati.

Sanquetta, C. R. et al. Inventário de plantas fornecedoras de produtos não madeireiros da Floresta Ombrófila Mista no Estado do Paraná. Scientia Agraria, v. 11, n. 5, p. 359-369, 2010. http://dx.doi. org/10.5380/rsa.v11i5.20222.

Santos, K. F. et al. Regeneração natural do componente arbóreo após a mortalidade de um maciço de taquara em um fragmento de Floresta Ombrófila Mista em Lages - SC. Ciência Florestal, v. 25, n. 1, p. 107-117, 2015. https://doi.org/10.5902/1980509817467.

Saueressig, D. Plantas do Brasil: árvores nativas. Irati: Plantas do Brasil, 2014. 432 p.

Sawczuk, A. R. Alteração na florística e estrutura horizontal de um fragmento de Floresta Ombrófila Mista na Floresta Nacional de Irati, Estado do Paraná. 2009. 164 f. Dissertação (Mestrado em Ciências Florestais) - Universidade Estadual do Centro Oeste, Irati.

Sccoti, M. S. V. et al. Mecanismos de regeneração natural em remanescentes de Floresta Estacional Decidual. Ciência Florestal, v. 21, n. 3, p. 459-472, 2011. http://dx.doi.org/10.5902/198050983803.

Silva, A. C. et al. Caracterização fitossociológica e fitogeográfica de um trecho de floresta ciliar em Alfredo Wagner, SC, como subsídio para restauração ecológica. Ciência Floresta, v. 23, n. 4, p. 579-593, 2013. http://dx.doi.org/10.5902/1980509812342.

Silva, M. M. et al. Regeneração natural em um remanescente de Floresta Ombrófila Mista, na Floresta Nacional de São Francisco de Paula, Rio Grande do Sul, Brasil. São Leopoldo: Instituto Anchietano de Pesquisas, 2010. p. 259-278. (Pesquisas, botânica, 61). 
Souza, R. P. M. et al. Estrutura e aspectos da regeneração natural de Floresta Ombrófila Mista no Parque Estadual de Campos do Jordão, SP, Brasil. Hoehnea, v. 39, n. 3, p. 387-407, 2012.
Valente, T. P. et al. Regeneração de Araucaria angustifólia em três fitofisionomias de um fragmento de Floresta Ombrófila Mista. Iheringia, Série Botânica, v. 65, n. 1, p. 17-24, 2010. 